\title{
Metabolic syndrome and risk of incident diabetes: findings from the European Prospective Investigation into Cancer and Nutrition-Potsdam Study
}

\author{
Earl S Ford*1, Matthias B Schulze ${ }^{2}$, Tobias Pischon ${ }^{3}$, Manuela M Bergmann³, \\ Hans-Georg Joost ${ }^{4}$ and Heiner Boeing ${ }^{3}$
}

\begin{abstract}
Address: ${ }^{1}$ Division of Adult and Community Health, National Center for Chronic Disease Prevention and Health Promotion, Centers for Disease Control and Prevention, Atlanta, Georgia, USA, ${ }^{2}$ Public Health Nutrition Unit, Technische Universität München, Center of Life and Food Sciences, Freising, Germany, ${ }^{3}$ Department of Epidemiology, German Institute for Human Nutrition (DIfE), Potsdam-Rehbrücke, Nuthetal, Germany and ${ }^{4}$ Department of Pharmacology, German Institute of Human Nutrition Potsdam-Rehbruecke, Nuthetal, Germany

Email: Earl S Ford* - eford@cdc.gov; Matthias B Schulze - matthias.schulze@wzw.tum.de; Tobias Pischon - pischon@dife.de; Manuela M Bergmann - bergmann@dife.de; Hans-Georg Joost - joost@dife.de; Heiner Boeing - boeing@dife.de

* Corresponding author
\end{abstract}

Published: 12 December 2008

Cardiovascular Diabetology 2008, 7:35 doi:10.1 186/1475-2840-7-35

This article is available from: http://www.cardiab.com/content/7///35

(c) 2008 Ford et al; licensee BioMed Central Ltd.

This is an Open Access article distributed under the terms of the Creative Commons Attribution License (http://creativecommons.org/licenses/by/2.0), which permits unrestricted use, distribution, and reproduction in any medium, provided the original work is properly cited.

\begin{abstract}
Background: Several aspects concerning the relationship between the metabolic syndrome and incident diabetes are incompletely understood including the magnitude of the risk estimate, potential gender differences in the associations between the metabolic syndrome and incident diabetes, the associations between the components of the metabolic syndrome and incident diabetes, and whether the metabolic syndrome provides additional prediction beyond its components. To shed light on these issues, we examined the prospective association between the metabolic syndrome defined by the National Cholesterol Education Program (NCEP) and International Diabetes Federation (IDF) and diabetes.

Methods: We used data for 2796 men and women aged 35-65 years from the European Prospective Investigation into Cancer and Nutrition-Potsdam Study followed for an average of 6.9 years. This analysis employed a case-cohort design that included 697 participants who developed diabetes and 2099 participants who did not. Incident diabetes was identified on the basis of self-reports and verified by contacting the patient's attending physician.

Results: The adjusted hazard ratio for the NCEP definition was 4.62 ( $95 \%$ confidence interval [Cl]: 3.905.48) and that for the IDF definition was 4.59 ( $95 \% \mathrm{Cl}: 3.84-5.50)$. The adjusted hazard ratios for the NCEP but not IDF definition were higher for women than men. When participants who had no cardiometabolic abnormalities were used as the reference group for the NCEP definition, the adjusted hazard ratio for having 3 or more abnormalities increased to 22.50 (95\% Cl: II.2I-45.19). Of the five components, abdominal obesity and hyperglycemia were most strongly associated with incident diabetes.

Conclusion: In this study population, both definitions of the metabolic syndrome provided similar estimates of relative risk for incident diabetes. The increase in risk for participants with the metabolic syndrome according to the NCEP definition was very large when contrasted with the risk among those who had no cardiometabolic abnormalities.
\end{abstract}




\section{Introduction}

The concept of the metabolic syndrome can be traced back to as early as 1923 when an association between hypertension, uric acid, and hyperglycemia was reported [1]. Since major organizations started formulating definitions for this syndrome in 1998, it has been the object of intense research. Although it has been shown to be a significant predictor of diabetes, cardiovascular disease, and all-cause mortality [2], controversy about its importance as a risk factor remains [3].

The most recent definition of the metabolic syndrome was developed by the International Diabetes Federation (IDF) in 2005 [4]. This definition places a major emphasis on central obesity. Since that time, several reports have examined the associations between the metabolic syndrome as defined by the IDF and incident diabetes and compared these risk estimates to those calculated using other definitions [5-13]. However, several issues remain unresolved including the presence of potential gender differences in the risk for incident diabetes associated with the metabolic syndrome and whether the metabolic syndrome offers additional prediction beyond its components. To examine these issues and to compare the ability of the metabolic syndrome to predict the risk of developing diabetes using two definitions, namely those of the National Cholesterol Education Program (NCEP) and IDF, we used data from a large prospective German study.

\section{Methods}

\section{Study population}

The European Prospective Investigation into Cancer and Nutrition (EPIC) Potsdam study is part of the multi-centre prospective cohort study EPIC $[14,15]$. In Potsdam, Germany, 27,548 subjects, 16,644 women mainly aged 3565 years and 10,904 men mainly aged 40-65 years, from the general population were recruited between 1994 and 1998 [16]. The baseline examination included anthropometric measurements, a personal interview including questions on prevalent diseases, and a questionnaire on socio-demographic and lifestyle characteristics. Follow-up questionnaires to identify incident cases of diabetes mellitus have been administered every 2 to 3 years. Response rates for each of the three waves of follow-up were about $95 \%$. We also considered questionnaires that were part of the ongoing fourth wave of follow-up round and were sent out until January 31st 2005. By August 31st 2005, $90 \%$ of them were returned. Consent was obtained from all participants of the study, and approval was given by the Ethical Committee of the State of Brandenburg, Germany. The conduct of the study was performed in accordance with principles of the Declaration of Helsinki.

\section{Ascertainment of incident type 2 diabetes}

Potentially incident cases of diabetes were those with selfreports of a diabetes diagnosis, diabetes-relevant medication, or dietary treatment due to diabetes. All potentially incident cases were verified by questionnaires mailed to the diagnosing physician asking about the date and type of diagnosis, diagnostic tests, and treatment of diabetes. Only cases with a physician diagnosis of type 2 diabetes (International Classification of Diseases, $10^{\text {th }}$ Revision: E11) and a diagnosis date after the baseline examination were considered as confirmed incident cases of type 2 diabetes and were used in the analysis.

\section{Ascertainment of prevalent type 2 diabetes}

Self-reported diabetes mellitus at baseline was evaluated by a study physician using information on self-reported medical diagnoses, medication records and dieting behavior. Uncertainties regarding a proper diagnosis were clarified with the participant or treating physician. We also used plasma concentrations of glucose to define prevalent diabetes. Because many participants did not provide fasting blood samples, we defined diabetes as a fasting plasma glucose $\geq 126 \mathrm{mg} / \mathrm{dl}$ or a nonfasting plasma glucose of $\geq 200 \mathrm{mg} / \mathrm{dl}$.

\section{Case-cohort construction}

The case-cohort consisted of a random sample of participants from the full cohort and all participants from the full cohort who developed incident diabetes. Thus, a random sample of 2,500 participants (subcohort) was drawn from the participants of the full cohort who had blood samples available $(26,444$ of 27,548$)$. After excluding participants with prevalent diabetes and missing information for study covariates, the subcohort included 2,165 participants. Of the 801 participants from the full cohort with blood samples who developed incident diabetes, 697 remained for analyses after the exclusion criteria were applied. Because the subcohort is representative of the full cohort at baseline in case-cohort studies, the random sample of the full cohort included 66 of the 697 subjects who developed incident type 2 diabetes during follow-up.

\section{Metabolic syndrome}

According to the IDF definition, someone has the metabolic syndrome if he or she has central adiposity plus $\geq 2$ of the following four factors [4]:

1. raised concentration of triglycerides: $\geq 150 \mathrm{mg} / \mathrm{dl}$ (1.7 $\mathrm{mmol} / \mathrm{L}$ ) or specific treatment for this lipid abnormality;

2. reduced concentration of high-density lipoprotein cholesterol: < $40 \mathrm{mg} / \mathrm{dl}(1.03 \mathrm{mmol} / \mathrm{L})$ in males and $<50 \mathrm{mg} /$ $\mathrm{dl}(1.29 \mathrm{mmol} / \mathrm{L})$ in females or specific treatment for this lipid abnormality; 
3. raised blood pressure: systolic blood pressure $\geq 130$ $\mathrm{mmHg}$ or diastolic blood pressure $\geq 85 \mathrm{mmHg}$ or treatment of previously diagnosed hypertension;

4. raised fasting plasma glucose $\geq 100 \mathrm{mg} / \mathrm{dl}(5.6 \mathrm{mmol} /$ l) or previously diagnosed type 2 diabetes.

For this study of German participants, we used a waist circumference threshold of $\geq 94 \mathrm{~cm}$ for men and $\geq 80 \mathrm{~cm}$ for women.

Using the 2004 National Heart, Lung, and Blood Institute/American Heart Association revision of the original NCEP criteria, participants who had three or more of the following criteria were defined as having the metabolic syndrome $[17,18]$ : 1 . abdominal obesity (waist circumference $>102 \mathrm{~cm}$ in men and $>88 \mathrm{~cm}$ in women); 2 . concentration of triglycerides $\geq 150 \mathrm{mg} / \mathrm{dl}(1.7 \mathrm{mmol} / \mathrm{l}) ; 3$. concentration of high-density lipoprotein cholesterol $<40$ $\mathrm{mg} / \mathrm{dl}(1.03 \mathrm{mmol} / \mathrm{l})$ in men and $<50 \mathrm{mg} / \mathrm{dl}(1.29 \mathrm{mmol} /$ l) in women; 4 . a systolic blood pressure $>=130 \mathrm{mmHg}$ or a diastolic blood pressure $\geq 85 \mathrm{mmHg}$ ); and 5. fasting glucose $\geq 100 \mathrm{mg} / \mathrm{dl}(5.6 \mathrm{mmol} / \mathrm{l})$. The participants who currently reported using antihypertensive were counted as having high blood pressure.

Anthropometric measurement procedures followed standard protocols under strict quality control $[19,20]$. Three measurements of systolic blood pressure and diastolic blood pressure from participants in the sitting position were recorded. The average of the last two readings was used. Concentrations of triglycerides, high-density lipoprotein cholesterol, and glucose were measured using the ADVIA 1650 chemistry system (Siemens Medical Solutions, Erlangen, Germany).

\section{Covariates}

We included the following covariates from the baseline data collection: age, sex, educational attainment, occupational activity, physical activity level, alcohol consumption, and concentrations of total cholesterol and Creactive protein. Information on educational attainment, smoking, occupational activity, and physical activity were assessed with a self-administered questionnaire and a personal interview. For physical activity, we considered participation in sports and bicycling, both calculated as the average time spent per week during the 12 months before baseline recruitment. Alcohol use was assessed as part of the food frequency questionnaire. Concentrations of total cholesterol and C-reactive protein, and glucose were measured using the ADVIA 1650 chemistry system (Siemens Medical Solutions, Erlangen, Germany).

\section{Statistical analyses}

The agreement in the classification of the metabolic syndrome using the two definitions was done with the kappa statistic. Differences in baseline characteristics by incident diabetes status were tested with Kruskal-Wallis tests for continuous variables and with Fisher's exact tests or chisquare tests for categorical variables. Cox proportional hazards analysis, using Prentice's pseudo-likelihood approach in the computations [21], was used to estimate hazard ratios and $95 \%$ confidence intervals. Age was used as the primary time dependent variable in all models, with entry time defined as the subject's age at recruitment and exit time as the date of diagnosis of diabetes, death, or return of the last follow-up questionnaire. Analyses were adjusted for baseline information including sex, educational attainment (in or no training, vocational training, technical school, technical college or university degree), smoking (never, past, current $<20$ cigarettes/d, current $\geq 20$ cigarettes/d), occupational activity (light, moderate, heavy), physical activity (continuous as h/ week), alcohol intake $(<0.1 \mathrm{~g} / \mathrm{d}, 0.1-5.0 \mathrm{~g} / \mathrm{d}, 5.1-10.0 \mathrm{~g} /$ d, $10.1-20.0 \mathrm{~g} / \mathrm{d}, 20.1-40.0 \mathrm{~g} / \mathrm{d},>40.0 \mathrm{~g} / \mathrm{d}$ ), and concentrations of total cholesterol (continuous) and C-reactive protein (continuous). All analyses were performed with SAS release 9.1 (SAS Institute, Cary, NC).

\section{Results}

Our final sample included 1186 men (397 events) and 1610 women (300 events). The mean and median followup times were 6.9 and 6.5 years, respectively. The prevalence of the metabolic syndrome according to the NCEP definition in the subcohort was $22.5 \%$ among all participants, $29.1 \%$ in men, and $18.5 \%$ in women. The prevalence of the metabolic syndrome according to the IDF definition in the subcohort was $28.3 \%$ among all participants, $33.2 \%$ in men, and $25.2 \%$ in women. The percent agreement between the two definitions was $87.4 \%$ (kappa $=0.67,95 \%$ confidence interval $[\mathrm{CI}]: 0.63,0.70)$ for all participants, $83 \%$ (kappa $=0.60,95 \%$ CI: $0.54,0.66)$ in men, and $90.2 \%$ (kappa $=0.72,95 \%$ CI: $0.67,0.76)$ in women.

At baseline, participants of the subcohort who developed diabetes were significantly more likely to be older, to have a larger waist circumference, higher systolic blood pressure, higher concentrations of total cholesterol, triglycerides, glucose, and C-reactive protein, and lower concentrations of high-density lipoprotein cholesterol than participants who did not develop diabetes (Table 1). Furthermore, participants who developed diabetes were far more likely to have had the metabolic syndrome at baseline than those who did not develop diabetes. Levels of physical activity, the percentage of participants who had never smoked, and the percentage of participants who 
Table I: Selected characteristics for the subcohort, by incident diabetes status, European Prospective Investigation into Cancer and Nutrition-Potsdam 1994-1998 to 2005

\begin{tabular}{|c|c|c|c|c|c|c|}
\hline & & \multicolumn{4}{|c|}{ Incident diabetes mellitus } & \multirow[b]{3}{*}{$\mathbf{p}$} \\
\hline & & \multicolumn{2}{|c|}{ No $(\mathbf{N}=2099)$} & \multicolumn{2}{|c|}{ Yes $(\mathbf{N}=66)$} & \\
\hline & & Mean or $\%$ & SD & Mean or \% & SD & \\
\hline Age (years) & & 49.5 & 8.8 & 55.9 & 7.0 & $<0.001$ \\
\hline Waist circumference $(\mathrm{cm})$ & & 85.0 & 12.4 & 98.6 & 11.2 & $<0.001$ \\
\hline Total cholesterol (mg/dl) & & 173.3 & 37.4 & 183.3 & 36.3 & 0.028 \\
\hline Triglycerides (mg/dl) & & 110.5 & 74.9 & 179.8 & 154.4 & $<0.001$ \\
\hline High-density lipoprotein cholesterol (mg/dl) & & 48.1 & 13.0 & 40.3 & 10.6 & $<0.001$ \\
\hline Systolic blood pressure $(\mathrm{mm} \mathrm{Hg})$ & & 128.6 & 17.4 & 143.8 & 21.2 & $<0.001$ \\
\hline Glucose $(\mathrm{mg} / \mathrm{dl})$ & & 86.9 & 15.0 & 103.4 & 21.5 & $<0.001$ \\
\hline C-reactive protein (mg/l) & & 1.6 & 2.7 & 4.4 & 7.3 & $<0.001$ \\
\hline Physical activity (h/w) & & 6.1 & 5.8 & 5.6 & 6.0 & 0.307 \\
\hline$\%$, Female & & 62.4 & -- & 50.0 & -- & 0.053 \\
\hline$\%$, Heavy occupational activity & & 6.1 & -- & 0.0 & -- & 0.031 \\
\hline$\%$, Never smokers & & 47.7 & -- & 39.4 & -- & 0.211 \\
\hline$\%$, Alcohol use $>40 \mathrm{~g} / \mathrm{d}$ & & 8.3 & -- & 10.6 & -- & 0.497 \\
\hline \multirow[t]{4}{*}{ Number of NCEP components } & & & & & & $<0.001$ \\
\hline & 0 & 19.6 & -- & 0.0 & -- & \\
\hline & $1-2$ & 59.6 & -- & 24.2 & -- & \\
\hline & $\geq 3$ & 20.8 & -- & 75.8 & -- & \\
\hline \%, Metabolic syndrome (NCEP) & & 20.8 & -- & 75.8 & -- & $<0.001$ \\
\hline$\%$, Metabolic syndrome (IDF) & & 26.8 & -- & 74.2 & -- & $<0.001$ \\
\hline
\end{tabular}

IDF = International Diabetes Federation, NCEP = National Cholesterol Education Program, SD = standard deviation

consumed $\geq 40$ grams of alcohol per day were not significantly different between the two groups.

Both definitions were significant predictors of incident diabetes (Table 2). The adjusted hazard ratio for the NCEP definition was 4.62 (95\% confidence interval [CI]: 3.90, 5.48 ) and that for the IDF definition was 4.59 (95\% CI: $3.84,5.50)$. When we limited the analyses to the subsample with fasting blood specimens ( $\mathrm{N}=788,189$ events), the adjusted hazard ratios were 4.83 (95\% CI: 3.46, 6.75) for the NCEP definition and 5.62 (95\% CI: 3.99, 7.92) for the IDF definition. The hazard ratios for women were larger than those for men only for the NCEP definition ( $p$ interaction for sex and metabolic syndrome $=0.001$ for NCEP and 0.325 for IDF).

For the NCEP definition, we also investigated the effect of using no cardiometabolic abnormalities as the reference group on the hazard ratio. The adjusted hazard ratio for

Table 2: Adjusted hazard ratios (95\% confidence interval) for incident diabetes by status of the metabolic syndrome among participants aged 35-65 years, European Prospective Investigation into Cancer and Nutrition-Potsdam Study $194-1998$ to 2005

\begin{tabular}{lc}
\hline Definition of metabolic syndrome & Hazard ratio (95\% Cl) \\
\hline National Cholesterol Education Program & $4.622(3.895,5.484)$ \\
Total (697 events, 2796 participants) & $3.687(2.943,4.619)$ \\
Men (397 events, I 186 participants) & $6.075(4.646,7.944)$ \\
Women (300 events, I610 participants) & $4.593(3.838,5.498)$ \\
International Diabetes Federation & $4.279(3.370,5.434)$ \\
Total (697 events, 2796 participants) & $4.785(3.615,6.333)$ \\
Men (397 events, I 186 participants) & \\
Women (300 events, I6I0 participants) &
\end{tabular}

Adjusted for age, sex, educational status, smoking status, alcohol use, physical activity, and concentrations of total cholesterol and C-reactive protein. 


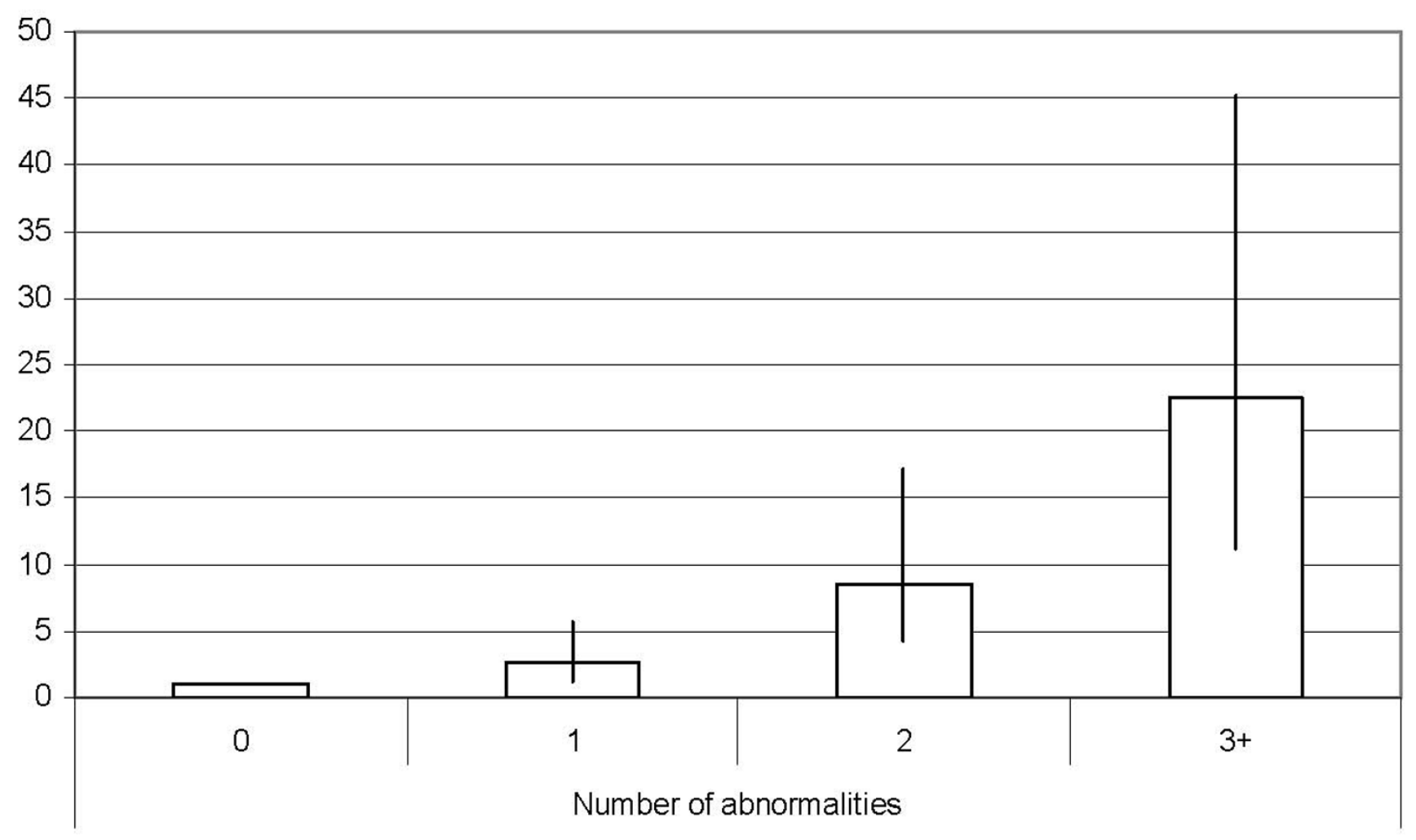

Figure I

Hazard ratios and $95 \%$ confidence intervals for incident diabetes among 2796 participants aged 35-65 years, by number of cardiometabolic abnormalities, EPIC-Potsdam I994-1998 to 2005. Hazard ratios are adjusted for age, sex, educational status, smoking status, alcohol use, occupational activity, physical activity, concentrations of total cholesterol and C-reactive protein, and other components of the metabolic syndrome.

having 3 or more abnormalities increased to $22.50(95 \%$ CI: 11.21, 45.19) (Figure 1).

Abdominal obesity $(\mathrm{HR}=2.81 ; 95 \% \mathrm{CI}: 2.36,3.33)$ and hyperglycemia $(\mathrm{HR}=2.67 ; 95 \% \mathrm{CI}: 2.26,3.16)$ were the two strongest predictors of incident diabetes and were of approximately similar magnitude (Table 3). They were followed in order of decreasing magnitude by low high- density lipoprotein cholesterol, high blood pressure, and hypertriglyceridemia. The magnitude of the hazard ratio for the NCEP definition of abdominal obesity was larger among women than men ( $\mathrm{p}$ interaction for abdominal obesity $=0.016$ ), but the hazard ratio for the IDF definition of abdominal obesity was similar for men and women ( $p$ interaction for abdominal obesity $=0.370$ ). Furthermore, the magnitude of the hazard ratio for hyper-

Table 3: Adjusted hazard ratios (95\% confidence interval) for incident diabetes by components of the metabolic syndrome among participants aged 35-65 years, European Prospective Investigation into Cancer and Nutrition-Potsdam Study $194-1998$ to 2005

\begin{tabular}{|c|c|c|c|c|c|c|c|}
\hline & $\mathbf{N}$ & $\begin{array}{c}\text { NCEP } \\
\text { abdominal } \\
\text { obesity }\end{array}$ & $\begin{array}{l}\text { IDF abdominal } \\
\text { obesity }\end{array}$ & $\begin{array}{c}\text { Hypertriglycerid } \\
\text { emia }\end{array}$ & $\begin{array}{l}\text { Low high-density } \\
\text { lipoprotein } \\
\text { cholesterol }\end{array}$ & $\begin{array}{l}\text { High blood } \\
\text { pressure }\end{array}$ & Hyperglycemia \\
\hline Total & 2796 & $2.81(2.36,3.33)$ & $2.90(2.29,3.67)$ & $1.26(1.06,1.5 \mathrm{I})$ & $1.97(1.64,2.37)$ & $1.52(1.22,1.90)$ & $2.67(2.26,3.16)$ \\
\hline Men & 1186 & $2.44(1.97,3.02)$ & $2.73(2.02,3.69)$ & $1.20(0.94,1.52)$ & $2.02(1.58,2.59)$ & $1.95(1.40,2.72)$ & $2.45(1.97,3.05)$ \\
\hline Women & 1610 & $3.62(2.67,4.90)$ & 3. $05(2.05,4.52)$ & $1.36(1.04,1.78)$ & $1.95(1.46,2.61)$ & $1.20(0.89,1.63)$ & $3.21(2.45,4.19)$ \\
\hline
\end{tabular}

IDF = International Diabetes Federation; NCEP = National Cholesterol Education Program.

Adjusted for age, sex, educational status, smoking status, alcohol use, occupational activity, physical activity, concentrations of total cholesterol and C-reactive protein, and other components of the metabolic syndrome. 
glycemia was higher among women than men (p interaction for hyperglycemia $=0.030$ ). For the other three components, there was no evidence for a gender effect ( $p$ for all interactions terms $>0.05$ ).

We also examined whether the metabolic syndrome provided prediction beyond that of its components. In models that included the five components in dichotomized form, as well as the covariates, the adjusted hazard ratio for the NCEP definition was 1.13 (95\% CI: 0.84, 1.52) (p Wald chi-square $=0.418$ ) and that for the IDF definition was 1.28 (95\% CI: $0.94,1.76)(\mathrm{p}$ Wald chi-square = $0.123)$.

\section{Discussion}

In this large prospective study, the metabolic syndrome was a strong predictor of incident diabetes. The NCEP but not the IDF definition of the metabolic syndrome proved to be a stronger predictor among women than men. Particularly, noteworthy was the high risk of developing diabetes when participants with the metabolic syndrome were compared with those who had no cardiometabolic abnormalities.

Our estimates of relative risk for the IDF definition were in line with those from other prospective studies that have examined the associations between the metabolic syndrome and incident diabetes. Most previous studies reported measures of relative risk ranging from 2.05 to 10.5 [5-13]. In comparison, the hazard ratio for all participants included in the analyses in the EPIC-Potsdam study was 4.59 .

Few studies have examined the gender-specific risks for incident diabetes associated with the metabolic syndrome $[22,23]$. In the Beijing Project, the magnitude of the relative risks was higher among men than women for all four definitions used in that study [22]. However, it was not clear whether the gender differences were statistically significant. In the Framingham Offspring Study, the relative risk among men was 6.92 (95\% CI: 4.47-10.81) and that among women was 6.90 (95\% CI: 4.35-10.94) [23]. In contrast, we found that women had a significantly higher hazard ratio when we used the NCEP definition but had a similar hazard ratio when we used the IDF definition. This difference likely emanates from one or both of the two key differences between the definitions. The first major difference is that, of the five components that are included in the two definitions, abdominal obesity is the only one that is defined differently. We did find a significant gender interaction with abdominal obesity for the NCEP definition but not the IDF definition. The second important difference is that the IDF definition requires the presence of abdominal obesity in contrast to the NCEP definition, which weights all components equally. Additional studies are needed to get a clearer picture of potential gender differences in the risk for incident diabetes associated with the metabolic syndrome.

The high hazard ratio for diabetes when we contrasted participants with 3 or more cardiometabolic abnormalities with those who had no abnormalities is consistent with results from previous studies. In the West of Scotland Coronary Prevention Study, men with 4 or more abnormalities had a hazard ration of 24.4 (95\% CI: 7.53-79.6) [24]. In the Framingham Offspring Study, odds ratios for those with 3 or more cardiometabolic abnormalities were 23.83 (95\% CI: 5.80-98.01) among men and 29.69 (95\% CI: 9.10-96.85) among women [23]. However, in an analysis of data from the British Regional Heart Study, participants with 3 abnormalities had a hazard ratio of 4.56 (95\% CI: $2.48,8.78)$ and participants with 4 or 5 abnormalities had a hazard ratio of 10.88 (95\% CI: 5.77, 20.50) compared with participants who had no abnormalities [25]. In the Caerphilly Cohort Study, the relative risks associated were 7.05 for 3 abnormalities and 13.39 for 4 abnormalities [26].

In other studies, impaired fasting glucose was the abnormality most strongly associated with incident diabetes [8$11,22,23,27]$. In the EPIC-Potsdam study, however, the hazard ratio for abdominal obesity was slightly higher than that for impaired fasting glucose.

In general, the few studies that have investigated the issue of whether the metabolic syndrome adds additional prediction for incident diabetes once its components are accounted for have concluded that this is not the case. However, only the WHO definition in men added additional prediction in a study conducted in Mauritius, and only the EGIR definition in men added additional prediction in the AusDiab $[10,11]$. In the EPIC-Potsdam study, the metabolic syndrome was also not a significant predictor of incident diabetes once its components were taken into account.

The hazard ratios for the two definitions were similar in our study. Given the high concordance in classifying participants as having or not having the syndrome in our study population, this is perhaps not too surprising. Most of the previous studies have found slightly higher estimates of relative risk for the NCEP definition than the IDF definition [5-13]. However, our calculations of the summary relative risks yielded estimates of a similar magnitude. Thus, the two definitions performed approximately similarly in predicting risk of new-onset diabetes.

Our study is subject to several limitations. First, incident diabetes was defined on the basis of self-reported data that were confirmed by physicians. Thus, we failed to detect 
undiagnosed cases of diabetes. However, if the association between the metabolic syndrome and undiagnosed diabetes was similar to that of diagnosed diabetes than our hazard ratios should be accurate [28]. Second, measurements of concentrations of glucose and triglycerides were measured on both fasting and nonfasting participants. We adjusted the threshold for defining diabetes to reflect nonfasting status. However, the percentage of participants with hypertriglyceridemia was likely overestimated. However, the subanalysis conducted on fasting participants who had fasted yielded similar hazard ratios to those of the full sample. Third, we were unable to adjust for some potential confounders such as family history of diabetes.

Considerable controversy surrounds the metabolic syndrome. Criticism has been leveled at the syndrome in part because of the dichotomization of the variables that have been included in the definitions. Undoubtedly the act of dichotomization results in some loss of predictive information and likely leads to a hereto undetermined underestimation of risk. Until the time comes when better risk functions that incorporate the continuous nature of these variables are developed and accepted by the medical community or when diabetes risk scores are conclusively shown to outperform the metabolic syndrome in predicting risk, a relatively simple tool like the metabolic syndrome can serve a useful function.

In conclusion, the metabolic syndrome was a strong predictor of incident diabetes in the EPIC-Potsdam study. The expression of this risk was particularly pronounced when participants with the metabolic syndrome were contrasted with those who had no cardiometabolic abnormalities. These findings reinforce the point that maximal risk reduction for contracting diabetes can be achieved by maintaining all five components that are included in the NCEP and IDF definitions of the metabolic syndrome in the normal range.

\section{Abbreviations}

EPIC: European Prospective Investigation into Cancer and Nutrition; IDF: International Diabetes Federation; NCEP: National Cholesterol Education Program.

\section{Competing interests}

The authors declare that they have no competing interests.

\section{Authors' contributions}

EF conceived the study, conducted the analyses, and prepared the manuscript. MS contributed to the analyses and to writing the manuscript. $\mathrm{TP}, \mathrm{MB}, \mathrm{HJ}$, and $\mathrm{HB}$ revised the manuscript for intellectual content. MS and HB supervised scientific issues of the study. All authors read and approved the final manuscript.
EF analyzed the data and drafted the manuscript; MS supervised the analysis of the data and helped draft the manuscript; TP participated in the study design and reviewed the manuscript; $\mathrm{MB}$ participated in the study design and reviewed the manuscript; $\mathrm{HJ}$ participated in the study design and reviewed the manuscript; $\mathrm{HB}$ was a principal investigator of the study and helped draft the manuscript.

\section{Disclaimer}

The findings and conclusions in this article are those of the authors and do not represent the official position of the Centers for Disease Control and Prevention.

\section{References}

I. Kylin E: Studien uber das Hypertonie-Hyperglykamie-Hyperurikamiesyndrom. Zentralbl Inn Med 1923, 44:105-127.

2. Ford ES: Risks for all-cause mortality, cardiovascular disease, and diabetes associated with the metabolic syndrome: a summary of the evidence. Diabetes Care 2005, 28: I769-1778.

3. Kahn R, Buse J, Ferrannini E, Stern M: The metabolic syndrome: time for a critical appraisal: joint statement from the American Diabetes Association and the European Association for the Study of Diabetes. Diabetes Care 2005, 28:2289-2304.

4. Alberti KG, Zimmet P, Shaw J: Metabolic syndrome - a new world-wide definition. A Consensus Statement from the International Diabetes Federation. Diabet Med 2006, 23:469-480.

5. Hanley AJ, Karter AJ, Williams K, Festa A, D'Agostino RB Jr, Wagenknecht LE, Haffner SM: Prediction of type 2 diabetes mellitus with alternative definitions of the metabolic syndrome: the Insulin Resistance Atherosclerosis Study. Circulation 2005, I | 2:37| 3-372| |

6. Lorenzo C, Williams K, Hunt KJ, Haffner SM: The National Cholesterol Education Program - Adult Treatment Panel III, International Diabetes Federation, and World Health Organization definitions of the metabolic syndrome as predictors of incident cardiovascular disease and diabetes. Diabetes Care 2007, 30:8-13.

7. Meigs JB, Rutter MK, Sullivan LM, Fox CS, D'Agostino RB Sr, Wilson PW: Impact of insulin resistance on risk of type 2 diabetes and cardiovascular disease in people with metabolic syndrome. Diabetes Care 2007, 30: 1219-1225.

8. Wang JJ, Li HB, Kinnunen L, Hu G, Jarvinen TM, Miettinen ME, Yuan $S$, Tuomilehto J: How well does the metabolic syndrome defined by five definitions predict incident diabetes and incident coronary heart disease in a Chinese population? Atherosclerosis 2007, 192:161-168.

9. Cheung BM, Wat NM, Man YB, Tam S, Thomas GN, Leung GM, Cheng $\mathrm{CH}$, Woo J, Janus ED, Lau CP, Lam TH, Lam KS: Development of diabetes in Chinese with the metabolic syndrome: a 6-year prospective study. Diabetes Care 2007, 30:1430-1436.

10. Cameron A], Zimmet PZ, Soderberg S, Alberti KG, Sicree R, Tuomilehto J, Chitson P, Shaw JE: The metabolic syndrome as a predictor of incident diabetes mellitus in Mauritius. Diabet Med 2007, 24: I 460-1469.

II. Cameron AJ, Magliano DJ, Zimmet PZ, Welborn TA, Colagiuri S, Tonkin AM, Shaw JE: The metabolic syndrome as a tool for predicting future diabetes: the AusDiab study. J Intern Med 2008, 264: $177-186$

12. Mannucci E, Monami M, Cresci B, Pala L, Bardini G, Petracca MG, Dicembrini I, Pasqua A, Buiatti E, Rotella CM: National Cholesterol Education Program and International Diabetes Federation definitions of metabolic syndrome in the prediction of diabetes: Results from the FIrenze-Bagno A Ripoli study. Diabetes Obes Metab 2008, 10:430-435.

13. Hadaegh F, Ghasemi A, Padyab M, Tohidi M, Azizi F: The metabolic syndrome and incident diabetes: Assessment of alternative definitions of the metabolic syndrome in an Iranian urban population. Diabetes Res Clin Pract 2008, 80:328-334. 
14. Boeing H, Wahrendorf J, Becker N: EPIC-Germany - A source for studies into diet and risk of chronic diseases. European Investigation into Cancer and Nutrition. Ann Nutr Metab 1999, 43:195-204.

15. Riboli E, Hunt KJ, Slimani N, Ferrari P, Norat T, Fahey M, Charrondiere UR, Hemon B, Casagrande C, Vignat J, Overvad K, Tjonneland A, Clavel-Chapelon F, Thiebaut A, Wahrendorf J, Boeing H, Trichopoulos D, Trichopoulou A, Vineis P, Palli D, Bueno-De-Mesquita HB, Peeters PH, Lund E, Engeset D, Gonzalez CA, Barricarte A, Berglund G, Hallmans G, Day NE, Key TJ, Kaaks R, Saracci R: European Prospective Investigation into Cancer and Nutrition (EPIC): study populations and data collection. Public Health Nutr 2002, 5:III3-II 24.

16. Boeing $H$, Korfmann A, Bergmann MM: Recruitment procedures of EPIC-Germany. European Investigation into Cancer and Nutrition. Ann Nutr Metab 1999, 43:205-2I5.

17. National Institutes of Health: Third Report of the National Cholesterol Education Program Expert Panel on Detection, Evaluation, and Treatment of High Blood Cholesterol in Adults (Adult Treatment Panel III). Executive Summary Bethesda, MD: National Institutes of Health, National Heart, Lung, and Blood Institute; (NIH Publication No. 0I-3670); $200 \mathrm{I}$.

18. Grundy SM, Brewer HB Jr, Cleeman JI, Smith SC Jr, Lenfant C: Definition of metabolic syndrome: report of the National Heart, Lung, and Blood Institute/American Heart Association conference on scientific issues related to definition. Circulation 2004, 109:433-438.

19. Klipstein-Grobusch K, Georg T, Boeing H: Interviewer variability in anthropometric measurements and estimates of body composition. Int J Epidemiol 1997, 26(SuppI I):SI74-I80.

20. Kroke A, Bergmann MM, Lotze G, Jeckel A, Klipstein-Grobusch K, Boeing $\mathrm{H}$ : Measures of quality control in the German component of the EPIC study. European Prospective Investigation into Cancer and Nutrition. Ann Nutr Metab 1999, 43:216-224.

21. Prentice RL: A case-cohort design for epidemiologic cohort studies and disease prevention trials. Biometrika 1986, 73:I-II.

22. Wang JJ, Hu G, Miettinen ME, Tuomilehto J: The metabolic syndrome and incident diabetes: assessment of four suggested definitions of the metabolic syndrome in a Chinese population with high post-prandial glucose. Horm Metab Res 2004, 36:708-715.

23. Sattar N, Gaw A, Scherbakova O, Ford I, O'Reilly DS, Haffner SM, Isles C, Macfarlane PW, Packard C], Cobbe SM, Shepherd J: Metabolic syndrome with and without $C$-reactive protein as a predictor of coronary heart disease and diabetes in the West of Scotland Coronary Prevention Study. Circulation 2003, 108:4|4-4|9.

24. Wilson PW, D'Agostino RB, Parise H, Sullivan L, Meigs JB: Metabolic syndrome as a precursor of cardiovascular disease and type 2 diabetes mellitus. Circulation 2005, I | 2:3066-3072.

25. Wannamethee SG, Shaper AG, Lennon L, Morris RW: Metabolic syndrome vs Framingham Risk Score for prediction of coronary heart disease, stroke, and type 2 diabetes mellitus. Arch Intern Med 2005, 165:2644-2650.

26. Elwood PC, Pickering JE, Fehily AM: Milk and dairy consumption, diabetes and the metabolic syndrome: the Caerphilly prospective study. J Epidemiol Community Health 2007, 61:695-698.

27. Macchia A, Levantesi G, Borrelli G, Franzosi MG, Maggioni AP, Marfisi R, Scarano M, Tavazzi L, Tognoni G, Valagussa F, Marchioli R, Associazione Nazionale Medici Cardiologi Ospedalieri; Istituto di Ricerche Farmacologiche Mario Negri-Consorzio Mario Negri Sud, Santa Maria Imbaro; Gruppo Italiano per lo Studio della Sopravvivenza nell'Infarto miocardico (GISSI)-Prevenzione Investigators: A clinically practicable diagnostic score for metabolic syndrome improves its predictivity of diabetes mellitus: the Gruppo Italiano per lo Studio della Sopravvivenza nell'Infarto miocardico (GISSI)Prevenzione scoring. Am Heart J 2006, I5 I:754.e7-754.el 7.

28. Rothman K, Greenland S: Modern Epidemiology 2nd edition. Philadelphia: Lippincott-Raven; 1998.

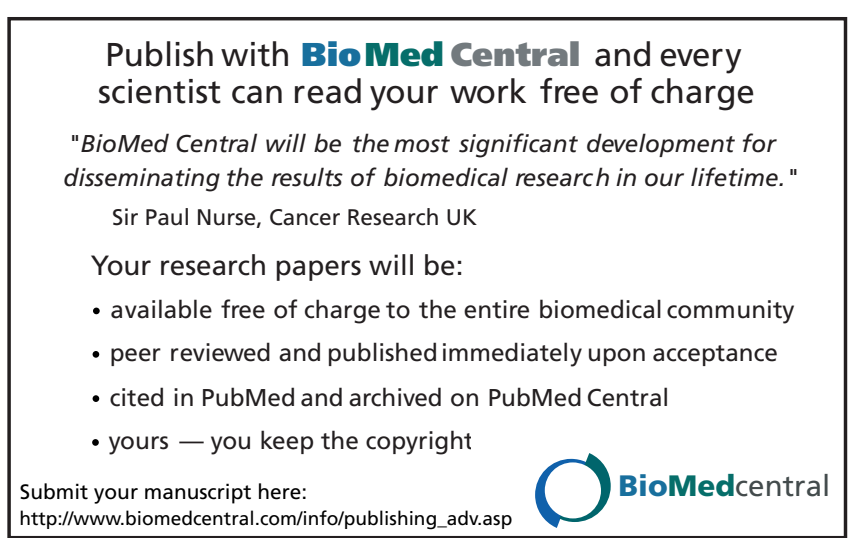

